\title{
Dual Role of a Ricinoleic Acid Derivative in the Aqueous Synthesis of Silver Nanoparticles
}

\author{
Isadora Dantas Costa, ${ }^{1}$ Alcides de Oliveira Wanderley Neto, ${ }^{2}$ \\ Heloiza Fernanda Oliveira da Silva, ${ }^{1}$ Edgar Perin Moraes, ${ }^{1}$ \\ Eryka Thamyris Damascena Nóbrega, ${ }^{1}$ Celso Sant'Anna, ${ }^{3}$ \\ Mateus Eugenio, ${ }^{3}$ and Luiz Henrique da Silva Gasparotto ${ }^{1}$ \\ ${ }^{1}$ Biological Chemistry and Chemometrics Research Group, Institute of Chemistry, Federal University of Rio Grande do Norte, \\ Lagoa Nova, 59072-970 Natal, RN, Brazil \\ ${ }^{2}$ Institute of Chemistry, Federal University of Rio Grande do Norte, Lagoa Nova, 59072-970 Natal, RN, Brazil \\ ${ }^{3}$ Laboratory of Microscopy Applied to Life Science-Lamav, National Institute of Metrology, Quality and Technology-Inmetro, \\ Duque de Caxias, 25250-020 Rio de Janeiro, RJ, Brazil
}

Correspondence should be addressed to Luiz Henrique da Silva Gasparotto; lhgasparotto@gmail.com

Received 8 November 2016; Revised 24 January 2017; Accepted 5 February 2017; Published 23 March 2017

Academic Editor: Piersandro Pallavicini

Copyright (C) 2017 Isadora Dantas Costa et al. This is an open access article distributed under the Creative Commons Attribution License, which permits unrestricted use, distribution, and reproduction in any medium, provided the original work is properly cited.

\begin{abstract}
We show that sodium 9,10-epoxy-12-hydroxytetradecanoate (SEAR), an epoxidized derivative of ricinoleic acid, simultaneously functioned as reducing and stabilizing agents in the synthesis of silver nanoparticles in alkaline aqueous medium. The advantage of using SEAR is its biodegradability and nontoxicity, which are important characteristics for mitigation of environmental impact upon discharge of nanoparticles into terrestrial and aquatic ecosystems. The SEAR concentration was found to impact considerably the size distribution of silver nanoparticles (AgNPs). A concentration below the SEAR critical micelle concentration (CMC) generated $23 \mathrm{~nm}$ sized AgNPs with $10 \mathrm{~nm}$ standard deviation, while $50 \mathrm{~nm}$ sized AgNPs $(\sigma=21 \mathrm{~nm})$ were obtained at a concentration above the SEAR CMC. FTIR analysis revealed that the carboxylate that constitutes the SEAR hydrophilic head binds directly to the AgNPs surface promoting stabilization in solution. Finally, AgNPs turned into $\mathrm{Ag}_{2} \mathrm{~S}$ upon contact with wastewater samples from Wastewater Treatment Plant at Federal University of Rio Grande do Norte (UFRN), Brazil, which is an interesting result, since $\mathrm{Ag}_{2} \mathrm{~S}$ is more environmentally friendly than pure AgNPs.
\end{abstract}

\section{Introduction}

Silver nanoparticles (AgNPs) have found innumerable applications that comprise biomedicine $[1,2]$, food storage [3], sensors [4], and (electro)catalysis [5, 6]. Concerning their synthesis, AgNPs may be produced via physical [7], biological [8], or chemical methods [9-11], being the latter more adequate in terms of cost, simplicity, and quantity of formed AgNPs. Chemical methods usually require reducing agents to convert $\mathrm{Ag}^{+}$into $\mathrm{Ag}^{0}$, followed by nucleation and growth that lead to metallic colloidal nanoparticles. Sodium borohydride [12] is the most widely used reagent for the reduction of metallic ions, despite the fact that most reactions involving it require further safety precautions due to their extreme exothermic nature $[13,14]$. Additionally, $\mathrm{NaBH}_{4}$ has to be used in large excess because it undergoes hydrolysis when brought into contact with water and metallic surfaces [15]. N,N-dimethylformamide [16] and hydrazine [17] have also been applied as reducing agents for the production of AgNPs. It is important to point out, however, that those chemicals must be carefully handled since they have been implicated in liver disease [18] and cancer [19], respectively. Another point worth mentioning is that nanoparticles require some sort of stabilization (electrostatic [20] or steric [21]) to guarantee 


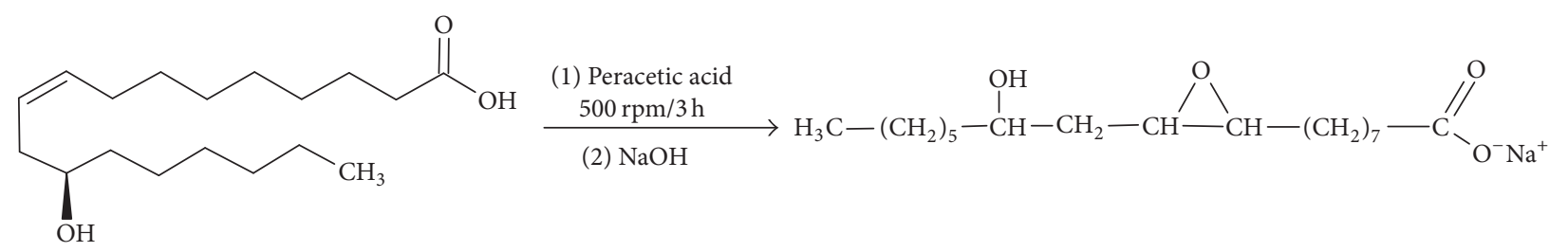

SCHEME 1: Epoxidation of ricinoleic acid.

their proper availability in solution. Needless to say, it is also desirable that a stabilizing agent be environmentallycompatible for safe handling of the final product.

Castor oil is a vegetable oil extracted from seeds of castor bean plant (Ricinus communis L.). Originally used as a laxative folk medicament, castor oil is nowadays employed predominantly in cosmetic industries as a cream base in formulations of skin moisturizers [22]. It is primarily constituted of ricinoleic acid (approximately 90\%), which can then be transformed into sodium ricinoleate via alkaline hydrolysis [23]. Teomim et al. [24] hypothesized the use of ricinoleatebased polymers as drug carriers due to their lack of toxicity when tested in rats. Vieira et al. [25] found that topical application of ricinoleic acid exerted exceptional analgesic and anti-inflammatory activity in rats. These features would make castor oil derivatives eligible for nanoparticle synthesis, provided that the 18-carbon fatty acid is capable of preventing aggregation and excessive nanoparticle growth. So far, studies have employed castor oil or ricinoleic acid as dispersive media for stabilization of a variety of nanostructures that include gold nanoparticles produced by sputtering [26] and wet chemistry process [27], quantum dots fabricated through thermolysis [28], and silver and gold nanoparticles in paints [29], as well as silver nanoparticles synthesized via ablation of metallic silver [30]. A question that remains open is whether ricinoleic acid/ricinoleate could function concomitantly as reducing and capping agents in appropriate experimental conditions.

Herein we showed, for the first time, that sodium 9,10-epoxy-12-hydroxytetradecanoate (SEAR), an epoxidized derivative of ricinoleic acid, simultaneously functions as reducing and stabilizing agents in the synthesis of silver nanoparticles in alkaline aqueous medium. Recently [31], we showed that molecules bearing hydroxyl groups can reduce gold and silver ions in alkaline media via formation of alkoxides that are the actual reducing agents. Although SEAR has a hydroxyl group at the C-12 position, it is not capable of reducing $\mathrm{Ag}^{+}$. On the other hand, stable AgNPs were obtained by substituting the double bond of the oil skeleton with an epoxide. The concentration of SEAR influenced the rate of AgNPs formation and their size distribution. Finally, we studied the behavior of SEAR-capped AgNPs spiked in sewage from a local wastewater treatment plant. Changes in the UV-Vis signal of the AgNPs suggested that these nanoparticles may be interesting sensor for chemical oxygen demand determination.

\section{Experimental}

\subsection{Synthesis of SEAR}

2.1.1. Castor Oil Alkaline Hydrolysis and Extraction of Ricinoleic Acid. The procedure has been adapted from the work by Castro Dantas et al. [32]. $30.0 \mathrm{~g}$ of castor oil was refluxed for $2 \mathrm{~h}$ with $6.0 \mathrm{~g}$ of $\mathrm{KOH}$ (Sigma-Aldrich) dissolved in a mixture of $60 \mathrm{~mL}$ of deionized water with $60.0 \mathrm{~mL}$ of ethanol (Synth). The product was then washed with water and had its $\mathrm{pH}$ adjusted to 4.5 with $30 \% \mathrm{H}_{2} \mathrm{SO}_{4}$ (Sigma-Aldrich). After adding $20 \mathrm{~mL}$ diethyl ether (Sigma-Aldrich), the organic phase (a mixture of fatty acids) was separated and mixed with $3.0 \mathrm{~g}$ of $\mathrm{Na}_{2} \mathrm{SO}_{4}$ (Sigma-Aldrich) to remove excess water. The mixture was then filtered, the diethyl ether (Synth) was removed in a rotary evaporator, and $50 \mathrm{~mL}$ of acetone (SigmaAldrich) was added to the fatty acid mixture which was then kept at $-10^{\circ} \mathrm{C}$ for $48 \mathrm{~h}$ to promote solidification of fatty acids other than the ricinoleic acid. Afterwards, the two-phase mixture was filtered to separate the liquid ricinoleic acid. Characterization of the ricinoleic acid by FTIR and NMR can be found in Supporting Information (see Supporting Information in the Supplementary Material available online at https://doi.org/10.1155/2017/1230467).

2.1.2. Epoxidation of Ricinoleic Acid and Saponification. Epoxidized ricinoleic acid was synthesized in a two-step process. Firstly, peracetic acid was obtained by slowly mixing $12.5 \mathrm{~g}$ of acetic anhydride (Sigma-Aldrich) with $11.6 \mathrm{~mL}$ of hydrogen peroxide (Sigma-Aldrich) in an ice bath. After 6 the mixture was stirred magnetically at $500 \mathrm{rpm}$ for $24 \mathrm{~h}, 20.0 \mathrm{~g}$ of ricinoleic acid was added to it, and the chemicals were allowed to react for $3 \mathrm{~h}$ in order to obtain the epoxidized ricinoleic acid. Saponification was then carried out by mechanically stirring the epoxidized ricinoleic acid with $1.2 \mathrm{~g}$ of $\mathrm{NaOH}$ (Sigma-Aldrich) until a white solid was obtained. The process is briefly presented in Scheme 1. The epoxidized ricinoleic acid was then characterized with FTIR and NMR (Supporting Information).

2.2. Synthesis and Characterization of SEAR-Capped AgNPs. The following stock solutions were prepared for the synthesis of AgNPs: $0.10 \mathrm{moll}^{-1} \mathrm{SEAR}, 10 \mathrm{mM} \mathrm{AgNO}_{3}$ (SigmaAldrich), and $1.0 \mathrm{moll}^{-1} \mathrm{NaOH}$ (Sigma-Aldrich). In a typical experiment at room temperature, $80 \mu \mathrm{l}$ of the $\mathrm{AgNO}_{3}$ solution is diluted in $1920 \mu \mathrm{l}$ of water. In another vessel, $400 \mu \mathrm{l}$ of the $\mathrm{NaOH}$ solution is added to either $40 \mu \mathrm{l}$ or $400 \mu \mathrm{l}$ of the SEAR 
solution with the final volume taken to $2.0 \mathrm{ml}$ through the addition of water. The SEAR $+\mathrm{NaOH}$ mixture is then poured into the diluted $\mathrm{AgNO}_{3}$ to form AgNPs.

UV-Vis was performed on an Ocean Optics USB-650 Tide spectrophotometer. Transmission electron microscopy (TEM) images were acquired with a FEI Tecnai $G^{2}$ Spirit BioTWIN microscope operating at $120 \mathrm{kV}$ and FTIR in ATR mode was carried out with a Bruker Vertex 70 spectrophotometer.

2.3. Reaction of AgNPs with Local Sewage. A real effluent (chemical oxygen demand $=920.0 \mathrm{mg} \mathrm{L}^{-1}$ ) was sampled at the Federal University of Rio Grande do Norte's wastewater treatment plant (ETE-UFRN) located in the northeast of Brazil. The wastewater is mostly composed of domestic effluents from the UFRN central campus. In order to monitor the reaction between the wastewater sample and AgNPs with $\mathrm{UV}$-Vis spectroscopy, $1.0 \mathrm{~mL}$ of wastewater was mixed with $1.0 \mathrm{~mL}$ of deionized water in a $1.0 \mathrm{~cm}$ path-length cuvette, followed by addition of $1.0 \mathrm{~mL}$ SEAR-capped AgNPs. UV-Vis spectra were then recorded at distinct times. In a separate experiment devised to check the constitution of the AgNPs after reacting with wastewater, $50 \mathrm{~mL}$ of wastewater was mixed with $50 \mathrm{~mL}$ of AgNPs $+50 \mathrm{~mL}$ of deionized water and allowed to rest for 15 days. Afterwards, the solution was centrifuged for $15 \mathrm{~min}$ and the supernatant was discarded. The AgNPs on the bottom of the flasks were then washed with deionized water to remove soluble species and centrifuged for another $15 \mathrm{~min}$. The AgNPs pellet was dried at $40^{\circ} \mathrm{C}$ for $4 \mathrm{~h}$ and subjected to energy-dispersive X-ray spectroscopy (EDS).

\section{Results and Discussion}

3.1. Synthesis and Characterization of SEAR-AgNPs. Gomes et al. [31] presented strong evidences that alkoxides from alcohols, aldehydes, and ketones are the actual reducing species in alkaline media for the generation of silver and gold nanoparticles. In that study, the authors argued that any molecule capable of generating an alkoxide would be eligible for reducing $\mathrm{Au}^{3+}, \mathrm{Ag}^{+}$, or a mixture of them, to form their respective nanoparticles. In the present case, SEAR has hydroxyl and epoxide groups in its skeleton. Since the experiments were conducted in alkaline medium, we hypothesized the hydroxyl group on SEAR tail would be deprotonated to some extent and the epoxide ring would be open generating more hydroxyl groups to act as reducing agents. The following results confirm that SEAR is indeed capable of reducing silver ions under the conditions employed in the present study. It is also important to take into consideration that the concentration of the capping agent (in the present study a role also played by SEAR) profoundly impacts on size and shape of nanoparticles, especially if the surfactant forms micelles [33]. Thus, we have selected SEAR concentrations of $1.0 \mathrm{mM}$ and $10.0 \mathrm{mM}$, which correspond to concentrations below and above the SEAR critical micelle concentration (CMC) [23], respectively, to evaluate their impact on the reduction of $\mathrm{Ag}^{+}$and posterior stabilization. Figures 1(a) and 1(b) show time-dependent UV-Vis spectra of solutions that resulted from the addition of SEAR to $\mathrm{AgNO}_{3}$ at room temperature and $\mathrm{pH}$ 13. Both solutions turned into yellow as a consequence of the formation of AgNPs. The yellow color is due to the surface plasmon band (SPB) that resulted from the resonant coherent dipolar oscillations of the electron gas (electrons of the conduction band) at the surface of nanoparticles [34]. The maximum wavelength in the colloidal AgNPs spectra after $24 \mathrm{~h}$ was $408 \mathrm{~nm}$ regardless of the SEAR concentration. Although the maximum wavelength [35] is a common parameter used to compare sizes of nanoparticles in a given matrix, a more detailed analysis is provided by the peak width at half maxima (PWHM) as studied by Brown et al. [36]. According to their concept, the smaller the PWHM value the narrower the size distribution of nanoparticles. Comparing the PWHM of AgNPs spectra obtained with $1.0 \mathrm{mM}$ and $10.0 \mathrm{mM}$ SEAR that have roughly the same absorbance $(\approx 1.30)$, the former and the latter concentrations resulted in $90 \mathrm{~nm}$ and $109 \mathrm{~nm}$, respectively, meaning that $1.0 \mathrm{mM}$ SEAR provided somewhat more uniform AgNPs. This result will be further investigated by TEM.

Figure 1(c) presents a plot of the absorbance at $408 \mathrm{~nm}$ as a function of time for AgNPs produced with $1.0 \mathrm{mM}$ (red solid circles) and $10.0 \mathrm{mM}$ (black solid squares) SEAR. Interestingly, the formation of AgNPs in both cases passed through an induction period (nucleation process) of approximately $40 \mathrm{~min}$ (Figure 1(c), inset) prior to exponential absorbance increase related to autocatalytic growth [37] of AgNPs. Another point is that the absorbances recorded at $1.0 \mathrm{mM}$ SEAR were slightly higher than those at $10.0 \mathrm{mM}$ SEAR up to $40 \mathrm{~min}$ (inset of Figure 1(c)). This is also observed in Figures 1(a) and 1(b), where initial spectra from AgNPs produced with $1.0 \mathrm{mM}$ SEAR already present a positive curvature, as opposed to those from $10.0 \mathrm{mM}$. These results may be reasoned by selecting the $\mathrm{CMC}$ as the parameter that divides the two behaviors: before the SEAR CMC of $9.2 \mathrm{mM} \mathrm{[23],}$ SEAR molecules are readily available in solution for the reduction of $\mathrm{Ag}^{+}$, leading to quick AgNPs nucleation. After the CMC, on the other hand, SEAR molecules incorporated into micelles must be liberated through disruption of the micelle structure in order to make -OH groups available for further reduction of $\mathrm{Ag}^{+}$. Since we are dealing with normalphase micelles, hydrophilic "heads" contact water while the hydrophobic tails containing - $\mathrm{OH}$ point to the micelle center. Therefore, we concluded that the nucleation process depends on free, soluble SEAR while autocatalytic growth would require disruption of micelles to liberate the $-\mathrm{OH}$ hidden in their core.

Figure 2 depicts TEM images of AgNPs produced with $1.0 \mathrm{mM}$ and 10.0 mM SEAR with their respective size distributions. As seen, the AgNPs were not monodisperse; however, those obtained with $10.0 \mathrm{mM}$ SEAR were substantially larger (51 $\mathrm{nm}$ on average) than those from $1.0 \mathrm{mM}$ SEAR $(21 \mathrm{~nm})$. The standard deviation also followed the same trend $(23 \mathrm{~nm}$, twice the value of that from $1.0 \mathrm{mM}$ SEAR). This result corroborates the PWHM analysis (Figures 1(a) and 1(b)). The micelle structure seems to have played an important role in controlling size and distribution of AgNPs. As shown in Scheme 2, SEAR interacts with silver through hydrophilic 


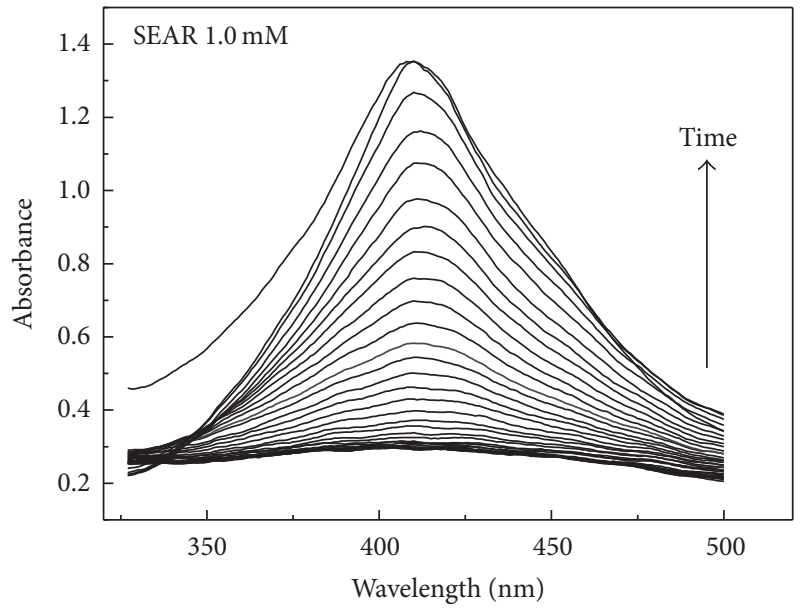

(a)

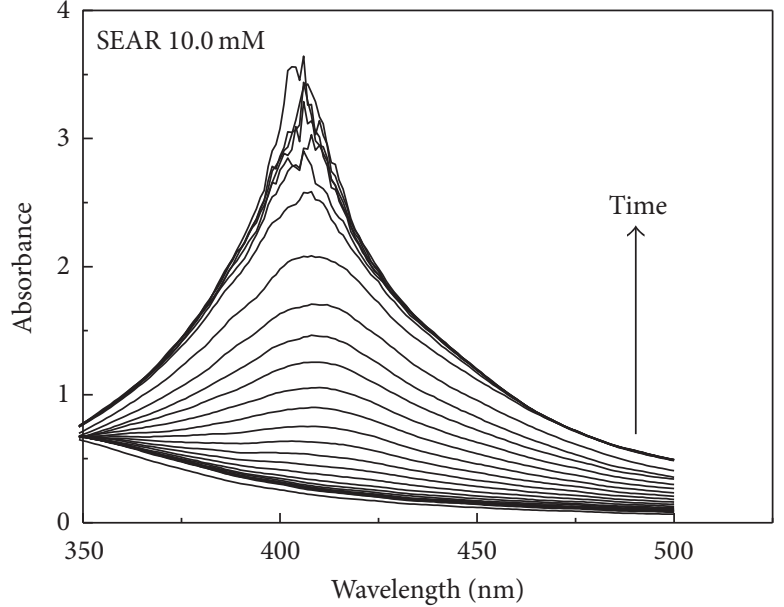

(b)

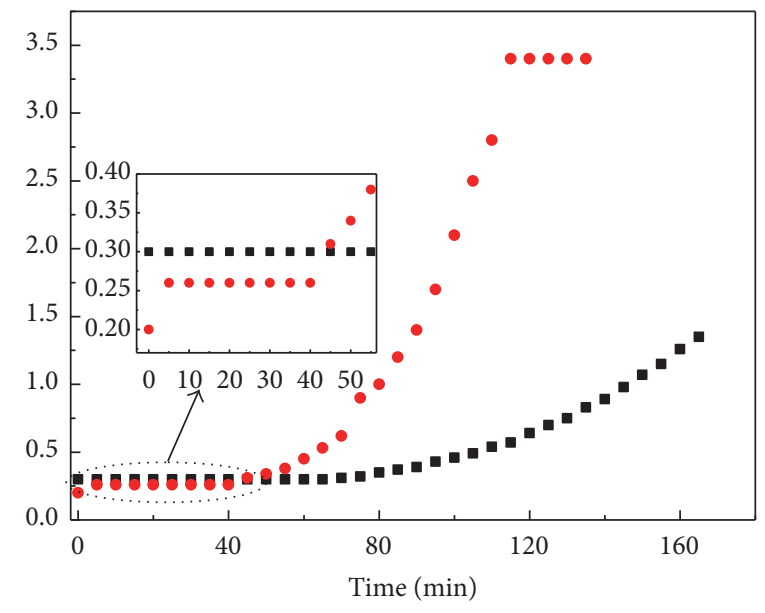

- SEAR $1.0 \mathrm{mM}$

- SEAR $10.0 \mathrm{mM}$

(c)

FIGURE 1: UV-Vis spectra of AgNPs produced with (a) $1.0 \mathrm{mM}$ SEAR (red solid circles) and (b) $10.0 \mathrm{mM}$ SEAR (black solid squares) recorded $5 \mathrm{~min}$ apart. (c) Evolution of absorbance at $408 \mathrm{~nm}$. Inset. Magnification of the region between $0 \mathrm{~min}$ and $50 \mathrm{~min}$. Other conditions: $\left[\mathrm{Ag}^{+}\right]=$ $0.20 \mathrm{mM},\left[\mathrm{OH}^{-}\right]=0.10 \mathrm{M}, \mathrm{T}=25^{\circ} \mathrm{C}$.
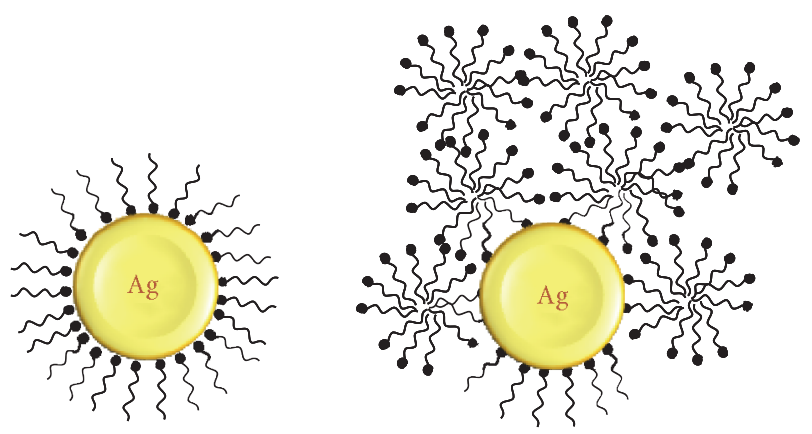

Scheme 2: On left and right sides AgNPs are stabilized by SEAR below and its above CMC, respectively.

heads (as shown later by ATR-FTIR). It is thus safe to assume that there would be a competition between free and micelle SEAR for Ag adsorption sites. At concentrations lower than the CMC, all SEAR molecules on the AgNPs surface interact through heads with AgNPs and the hydrophobic tails prevent excessive nanoparticle growth through steric hindrance. In contrast, at concentrations higher than the CMC, not all SEAR molecules on the AgNPs surface were directly bound to it because the spherical nature of the micelle makes some SEAR molecules point away from the AgNP surface. The micelle structure may not be as effective as free SEAR molecules in stabilizing Ag nuclei, which then led to larger nanoparticles and broader size distribution probably through Ostwald ripening [38].

FTIR spectra in ATR mode of pure SEAR and SEARcapped silver nanoparticles are presented in Figure 3. As the most relevant region of the SEAR spectrum comprising the range of $1200-1800 \mathrm{~cm}^{-1}$, only this region has been analyzed in detail. The FTIR spectrum of pure SEAR (black line) displayed asymmetrical and symmetrical carboxylate stretching modes at $1564 \mathrm{~cm}^{-1}$ and $1410 \mathrm{~cm}^{-1}$, respectively [39]. 

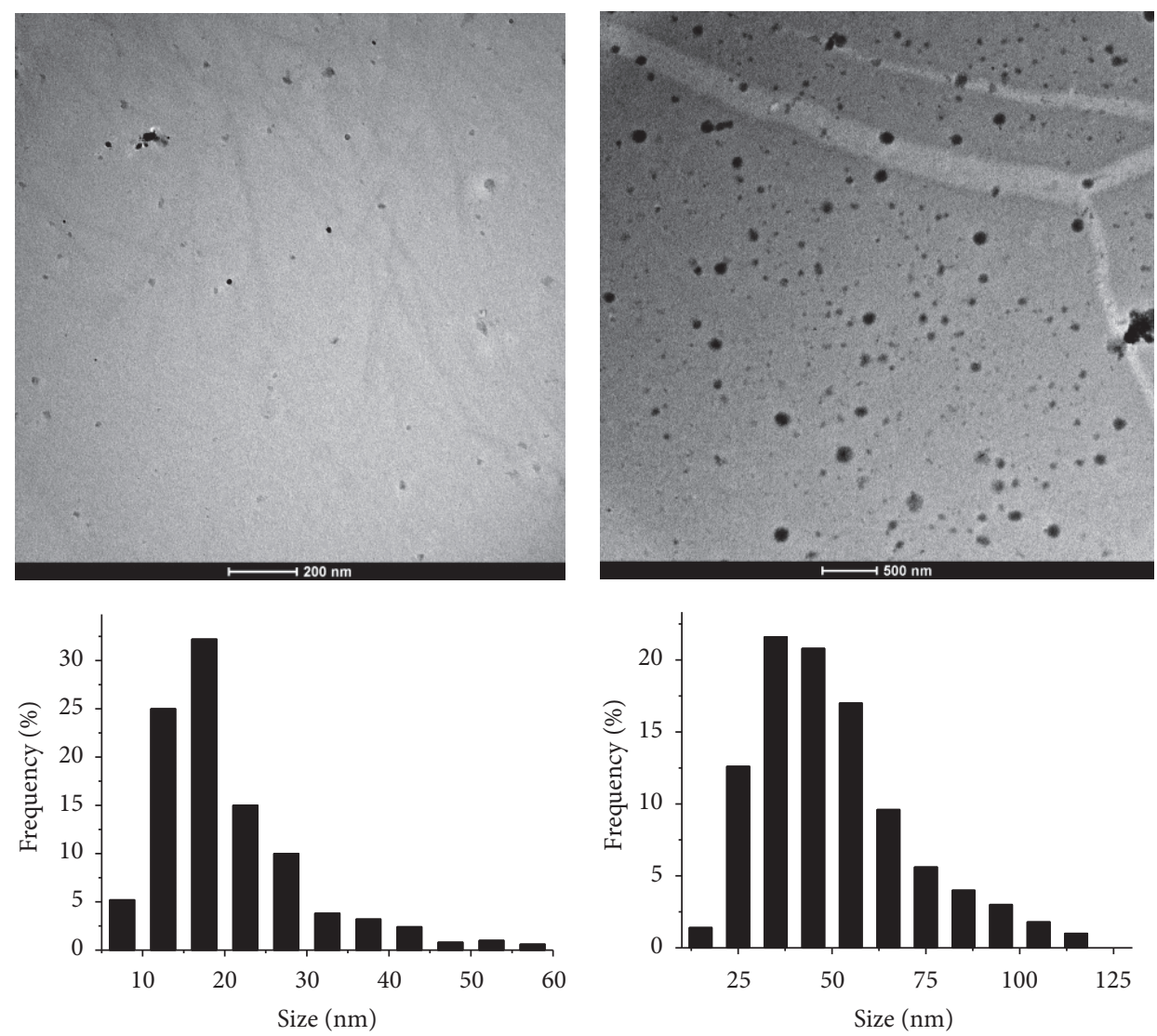

(a)

(b)

FIGURE 2: TEM images of AgNPs obtained with (a) $1.0 \mathrm{mM}$ and (b) $10.0 \mathrm{mM}$ SEAR. Other conditions: $\left[\mathrm{Ag}^{+}\right]=0.20 \mathrm{mM}^{-}\left[\mathrm{OH}^{-}\right]=0.10 \mathrm{M}$, $T=25^{\circ} \mathrm{C}$.

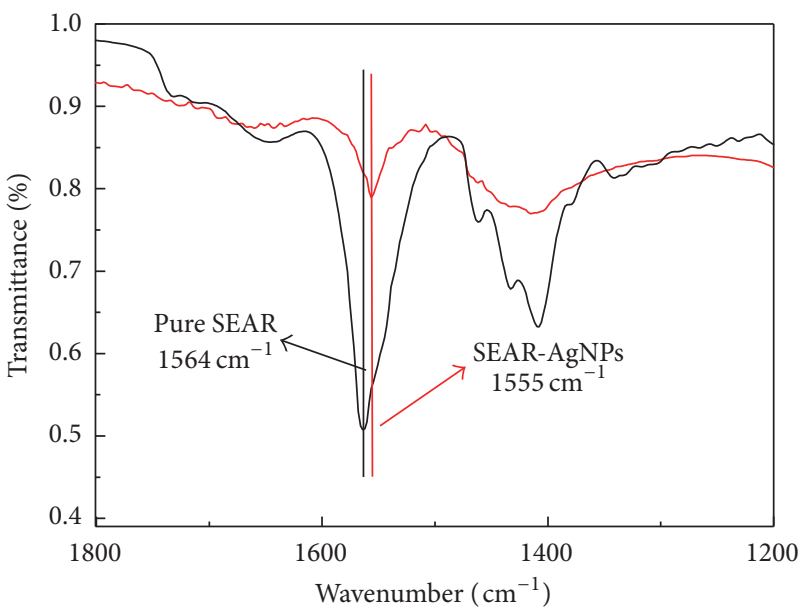

FIGURE 3: FTIR in ATR mode of pure SEAR (black line) and SEARcapped AgNPs (red line).

Upon stabilization of AgNPs (red line), the center of the asymmetrical stretching band shifts to $1555 \mathrm{~cm}^{-1}$ and the shoulders of the band related to the symmetrical stretching are considerably suppressed. This observation suggests that stabilization of AgNPs occurs via interaction between the
SEAR carboxylate and metallic silver. The fact that the asymmetrical stretching mode is shifted to a lower frequency suggests that both oxygen atoms from carboxylate donate an electron pair to vacant silver orbitals, decreasing, in turn, the double bond character due to interference with the carboxylate resonance system that probably chelated with silver symmetrically [40].

AgNPs have found a myriad of applications that comprise cosmetics, textiles, and food packaging. Inevitably, waste from those products will end up in terrestrial and aquatic ecosystems impacting biotic niche. We have therefore carried out experiments on the behavior of AgNPs in raw sewage from a local wastewater treatment plant in order to determine the fate of the AgNPs upon contact with a real-life system. Similar studies conducted with AgNPs stabilized by citrate [41], polyvinylpyrrolidone [41-43], and TWEEN [41] revealed that silver nanoparticles are prone to sulfidation that leads to $\mathrm{Ag}_{2} \mathrm{~S}$, which decreased silver nanoparticle toxicity towards a variety of terrestrial eukaryotic organisms [42]. As we envisage the herein produced AgNPs in a variety of applications, it is thus imperative to find out whether they can be transformed into $\mathrm{Ag}_{2} \mathrm{~S}$ in order to mitigate their environmental impact. Figure 4 presents time-dependent UV-Vis spectra of AgNPs in contact with raw sewage, where AgNPs produced with $1.0 \mathrm{mM}$ SEAR (Figure $4(\mathrm{a})$ ) are consumed 


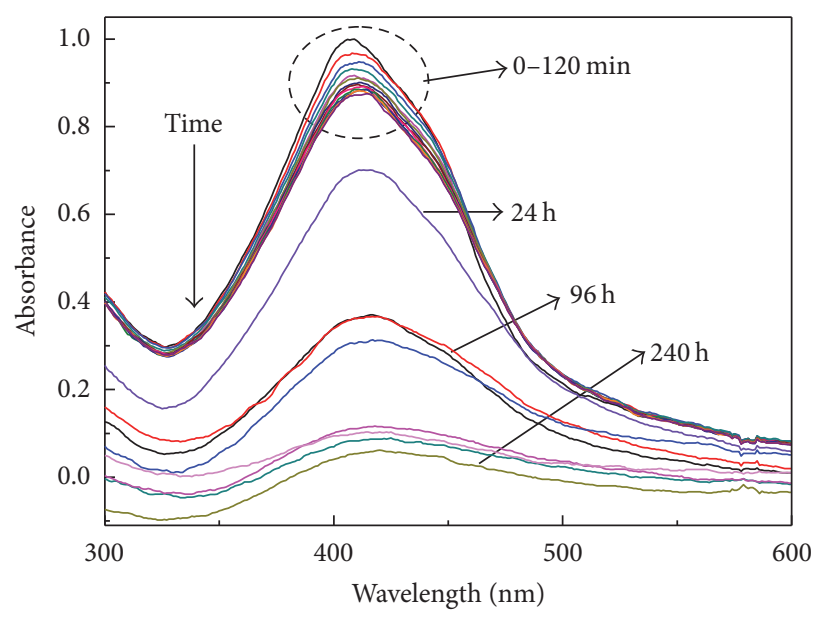

(a)

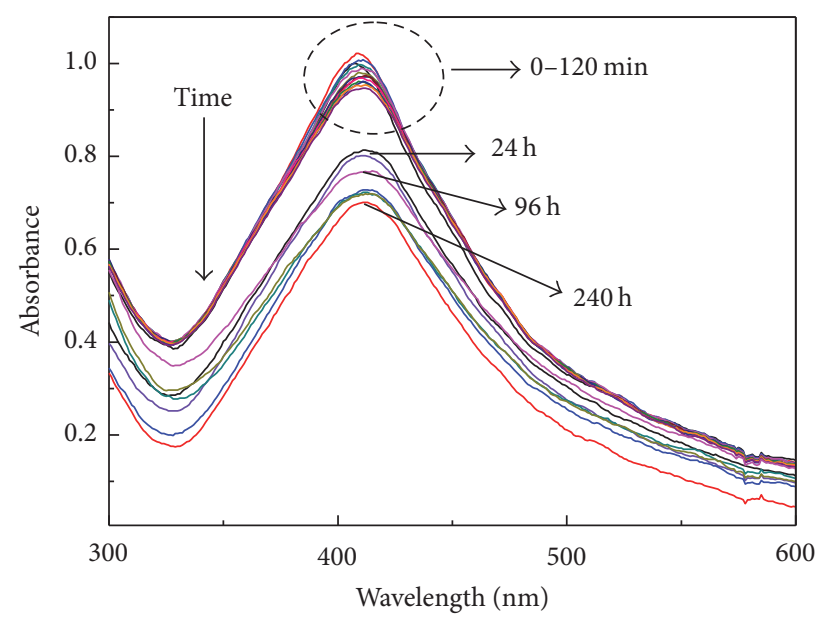

(b)

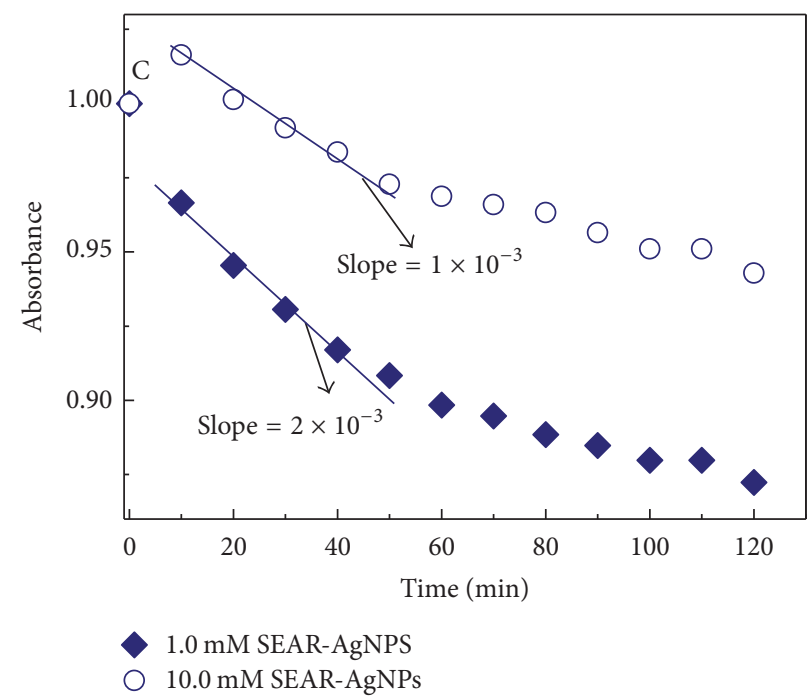

(c)

FIGURE 4: UV-Vis spectra of AgNPs produced with (a) $1.0 \mathrm{mM}$ SEAR and (b) $10.0 \mathrm{mM}$ SEAR in contact with raw sewage. (c) Absorbance recorded at $408 \mathrm{~nm}$ as a function of time for AgNPs.

more quickly than those synthesized with $10.0 \mathrm{mM}$ SEAR (Figure 4(b)), as revealed by the decrease of the surface plasmon resonance (SPB) with time. After 10 days, the intensities of SPB from AgNPs produced with $1.0 \mathrm{mM}$ and $10.0 \mathrm{mM}$ SEAR were 0.060 and 0.71 , respectively, showing that the latter is somewhat shielded from sulfidation. Figure 4(c) presents the rate of absorbance decrease at $408 \mathrm{~nm}$ for AgNPs produced at both SEAR concentrations. The slopes calculated for both curves show that the sulfidation is faster with AgNPs from 1.0 mM SEAR even in the beginning of the reaction. This result is probably a consequence of a higher concentration of SEAR around the particle in the case of $10.0 \mathrm{mM}$ SEAR, thus hampering the access of sulfur-containing species to the nanoparticle surface. The nanoparticle size is another factor that may have played a role in sulfidation. Kaegi et al. [41] found that smaller silver nanoparticles are subjected to higher degree of sulfidation than bigger nanoparticles, a result that corroborates those found in the present work. EDS conducted on AgNPs that reacted with raw sewage revealed the presence of sulfur confirming that sulfidation took place. At this point we are not able to determine whether sulfur is located only on the surface of the AgNPs or in their interior as well. Although the structure of the silver sulfide nanoparticles remains elusive (it is beyond the scope of the present study), the fact that the AgNPs produced herein are indeed prone to sulfidation makes them adequate for a variety of real-life applications.

\section{Conclusion}

We have shown that SEAR, a surfactant derived from ricinoleic acid, is capable of acting as reducing and capping agents in the synthesis of silver nanoparticles in alkaline medium. The fact that SEAR may form micelles had an impact on size and distribution of AgNPs. Finally, in addition to SEAR being environmentally benign, the toxicological 
effects of AgNPs on the environment are mitigated because AgNPs are subjected to sulfidation upon contact with raw sewage. These findings may propel these AgNPs into broader field of applications such as sensors and environmental remediation.

\section{Competing Interests}

The authors declare that they have no competing interests.

\section{References}

[1] C. Marambio-Jones and E. M. V. Hoek, "A review of the antibacterial effects of silver nanomaterials and potential implications for human health and the environment," Journal of Nanoparticle Research, vol. 12, no. 5, pp. 1531-1551, 2010.

[2] H. F. O. Silva, K. M. G. Lima, M. B. Cardoso et al., "Doxycycline conjugated with polyvinylpyrrolidone-encapsulated silver nanoparticles: a polymer's malevolent touch against Escherichia coli," RSC Advances, vol. 5, no. 82, pp. 66886-66893, 2015.

[3] R. Tankhiwale and S. K. Bajpai, "Graft copolymerization onto cellulose-based filter paper and its further development as silver nanoparticles loaded antibacterial food-packaging material," Colloids and Surfaces B: Biointerfaces, vol. 69, no. 2, pp. 164-168, 2009.

[4] P. Vasileva, B. Donkova, I. Karadjova, and C. Dushkin, "Synthesis of starch-stabilized silver nanoparticles and their application as a surface plasmon resonance-based sensor of hydrogen peroxide," Colloids and Surfaces A: Physicochemical and Engineering Aspects, vol. 382, no. 1-3, pp. 203-210, 2011.

[5] A. C. Garcia, L. H. S. Gasparotto, J. F. Gomes, and G. TremiliosiFilho, "Straightforward synthesis of carbon-supported Ag nanoparticles and their application for the oxygen reduction reaction," Electrocatalysis, vol. 3, no. 2, pp. 147-152, 2012.

[6] Z.-J. Jiang, C.-Y. Liu, and L.-W. Sun, "Catalytic properties of silver nanoparticles supported on silica spheres," Journal of Physical Chemistry B, vol. 109, no. 5, pp. 1730-1735, 2005.

[7] T. Tsuji, D.-H. Thang, Y. Okazaki, M. Nakanishi, Y. Tsuboi, and M. Tsuji, "Preparation of silver nanoparticles by laser ablation in polyvinylpyrrolidone solutions," Applied Surface Science, vol. 254, no. 16, pp. 5224-5230, 2008.

[8] N. Vigneshwaran, N. M. Ashtaputre, P. V. Varadarajan, R. P. Nachane, K. M. Paralikar, and R. H. Balasubramanya, "Biological synthesis of silver nanoparticles using the fungus Aspergillus flavus," Materials Letters, vol. 61, no. 6, pp. 1413-1418, 2007.

[9] H. Wang, X. Qiao, J. Chen, and S. Ding, "Preparation of silver nanoparticles by chemical reduction method," Colloids and Surfaces A: Physicochemical and Engineering Aspects, vol. 256, no. 2-3, pp. 111-115, 2005.

[10] M. M. Oliveira, D. Ugarte, D. Zanchet, and A. J. G. Zarbin, "Influence of synthetic parameters on the size, structure, and stability of dodecanethiol-stabilized silver nanoparticles," Journal of Colloid and Interface Science, vol. 292, no. 2, pp. 429-435, 2005.

[11] A. G. Garcia, P. P. Lopes, J. F. Gomes et al., "Eco-friendly synthesis of bimetallic AuAg nanoparticles," New Journal of Chemistry, vol. 38, no. 7, pp. 2865-2873, 2014.

[12] T. Maneerung, S. Tokura, and R. Rujiravanit, "Impregnation of silver nanoparticles into bacterial cellulose for antimicrobial wound dressing," Carbohydrate Polymers, vol. 72, no. 1, pp. 4351, 2008.
[13] J. Zhang, T. S. Fisher, J. P. Gore, D. Hazra, and P. V. Ramachandran, "Heat of reaction measurements of sodium borohydride alcoholysis and hydrolysis," International Journal of Hydrogen Energy, vol. 31, no. 15, pp. 2292-2298, 2006.

[14] S. W. Chaikin and W. G. Brown, "Reduction of aldehydes, ketones and acid chlorides by sodium borohydride," Journal of the American Chemical Society, vol. 71, no. 1, pp. 122-125, 1949.

[15] U. B. Demirci, O. Akdim, J. Andrieux, J. Hannauer, R. Chamoun, and P. Miele, "Sodium borohydride hydrolysis as hydrogen generator: issues, state of the art and applicability upstream from a fuel cell," Fuel Cells, vol. 10, no. 3, pp. 335-350, 2010.

[16] I. Pastoriza-Santos and M. Liz-Marzán, "Formation and stabilization of silver nanoparticles through reduction by $N, N$ dimethylformamide," Langmuir, vol. 15, no. 4, pp. 948-951, 1999.

[17] Y. Li, Y. Wu, and B. S. Ong, "Facile synthesis of silver nanoparticles useful for fabrication of high-conductivity elements for printed electronics," Journal of the American Chemical Society, vol. 127, no. 10, pp. 3266-3267, 2005.

[18] C. A. Redlich, W. S. Beckett, J. Sparer et al., "Liver disease associated with occupational exposure to the solvent dimethylformamide," Annals of Internal Medicine, vol. 108, no. 5, pp. 680 686, 1988.

[19] B. Ritz, Y. Zhao, A. Krishnadasan, N. Kennedy, and H. Morgenstern, "Estimated effects of hydrazine exposure on cancer incidence and mortality in aerospace workers," Epidemiology, vol. 17, no. 2, pp. 154-161, 2006.

[20] N. Mandzy, E. Grulke, and T. Druffel, "Breakage of $\mathrm{TiO}_{2}$ agglomerates in electrostatically stabilized aqueous dispersions," Powder Technology, vol. 160, no. 2, pp. 121-126, 2005.

[21] D. H. Napper, "Steric stabilization," Journal of Colloid And Interface Science, vol. 58, no. 2, pp. 390-407, 1977.

[22] G. A. Burdock, I. G. Carabin, and J. C. Griffiths, “Toxicology and pharmacology of sodium ricinoleate," Food and Chemical Toxicology, vol. 44, no. 10, pp. 1689-1698, 2006.

[23] A. de Oliveira Wanderley Neto, T. Neuma de Castro Dantas, A. A. Dantas Neto, and A. Gurgel, "Recent advances on the use of surfactant systems as inhibitors of corrosion on metallic surfaces," in The Role of Colloidal Systems in Environmental Protection, pp. 479-508, Elsevier, Amsterdam, The Netherlands, 2014.

[24] D. Teomim, A. Nyska, and A. J. Domb, "Ricinoleic acid-based biopolymers," Journal of Biomedical Materials Research, vol. 45, no. 3, pp. 258-267, 1999.

[25] C. Vieira, S. Evangelista, R. Cirillo, A. Lippi, C. A. Maggi, and S. Manzini, "Effect of ricinoleic acid in acute and subchronic experimental models of inflammation," Mediators of Inflammation, vol. 9, no. 5, pp. 223-228, 2000.

[26] H. Wender, L. F. De Oliveira, A. F. Feil et al., "Synthesis of gold nanoparticles in a biocompatible fluid from sputtering deposition onto castor oil," Chemical Communications, vol. 46, no. 37, pp. 7019-7021, 2010.

[27] S. F. A. Morais, M. G. A. Da Silva, S. M. P. Meneghetti, and M. R. Meneghetti, "Colloids based on gold nanoparticles dispersed in castor oil: Synthesis parameters and the effect of the free fatty acid content," Comptes Rendus Chimie, vol. 18, no. 4, pp. 410421, 2015.

[28] G. B. Shombe, E. B. Mubofu, S. Mlowe, and N. Revaprasadu, "Synthesis and characterization of castor oil and ricinoleic acid capped CdS nanoparticles using single source precursors," Materials Science in Semiconductor Processing, vol. 43, pp. 230237, 2016. 
[29] A. Kumar, P. K. Vemula, P. M. Ajayan, and G. John, "Silvernanoparticle-embedded antimicrobial paints based on vegetable oil," Nature Materials, vol. 7, no. 3, pp. 236-241, 2008.

[30] R. Zamiri, A. Zakaria, H. Abbastabar, M. Darroudi, M. S. Husin, and M. A. Mahdi, "Laser-fabricated castor oil-capped silver nanoparticles," International Journal of Nanomedicine, vol. 6, no. 1, pp. 565-568, 2011.

[31] J. F. Gomes, A. C. Garcia, E. B. Ferreira et al., "New insights into the formation mechanism of $\mathrm{Ag}, \mathrm{Au}$ and $\mathrm{AgAu}$ nanoparticles in aqueous alkaline media: alkoxides from alcohols, aldehydes and ketones as universal reducing agents," Physical Chemistry Chemical Physics, vol. 17, no. 33, pp. 21683-21693, 2015.

[32] T. N. Castro Dantas, E. Ferreira Moura, H. Scatena Júnior, A. A. Dantas Neto, and A. Gurgel, "Micellization and adsorption thermodynamics of novel ionic surfactants at fluid interfaces," Colloids and Surfaces A: Physicochemical and Engineering Aspects, vol. 207, no. 1-3, pp. 243-252, 2002.

[33] Y.-Y. Yu, S.-S. Chang, C.-L. Lee, and C. R. C. Wang, "Gold nanorods: electrochemical synthesis and optical properties," Journal of Physical Chemistry B, vol. 101, no. 34, pp. 6661-6664, 1997.

[34] P. Mulvaney, "Surface plasmon spectroscopy of nanosized metal particles," Langmuir, vol. 12, no. 3, pp. 788-800, 1996.

[35] E. Saion, E. Gharibshahi, and K. Naghavi, "Size-controlled and optical properties of monodispersed silver nanoparticles synthesized by the radiolytic reduction method," International Journal of Molecular Sciences, vol. 14, no. 4, pp. 7880-7896, 2013.

[36] K. R. Brown, D. G. Walter, and M. J. Natan, "Seeding of colloidal $\mathrm{Au}$ nanoparticle solutions. 2. Improved control of particle size and shape," Chemistry of Materials, vol. 12, no. 2, pp. 306-313, 2000.

[37] K. Esumi, T. Hosoya, A. Suzuki, and K. Torigoe, "Formation of gold and silver nanoparticles in aqueous solution of sugarpersubstituted poly(amidoamine) dendrimers," Journal of Colloid and Interface Science, vol. 226, no. 2, pp. 346-352, 2000.

[38] J. Polte, "Fundamental growth principles of colloidal metal nanoparticles-a new perspective," CrystEngComm, vol. 17, no. 36, pp. 6809-6830, 2015.

[39] J. Oomens and J. D. Steill, "Free carboxylate stretching modes," The Journal of Physical Chemistry A, vol. 112, no. 15, pp. 32813283, 2008.

[40] G. B. Deacon, F. Huber, and R. J. Phillips, "Diagnosis of the nature of carboxylate coordination from the direction of shifts of carbonoxygen stretching frequencies," Inorganica Chimica Acta, vol. 104, no. 1, pp. 41-45, 1985.

[41] R. Kaegi, A. Voegelin, C. Ort et al., "Fate and transformation of silver nanoparticles in urban wastewater systems," Water Research, vol. 47, no. 12, pp. 3866-3877, 2013.

[42] C. Levard, E. M. Hotze, B. P. Colman et al., "Sulfidation of silver nanoparticles: natural antidote to their toxicity," Environmental Science and Technology, vol. 47, no. 23, pp. 13440-13448, 2013.

[43] C. M. Levard, B. C. Reinsch, F. M. Michel, C. Oumahi, G. V. Lowry, and G. E. Brown, "Sulfidation processes of PVP-coated silver nanoparticles in aqueous solution: impact on dissolution rate," Environmental Science \& Technology, vol. 45, no. 12, pp. 5260-5266, 2011. 

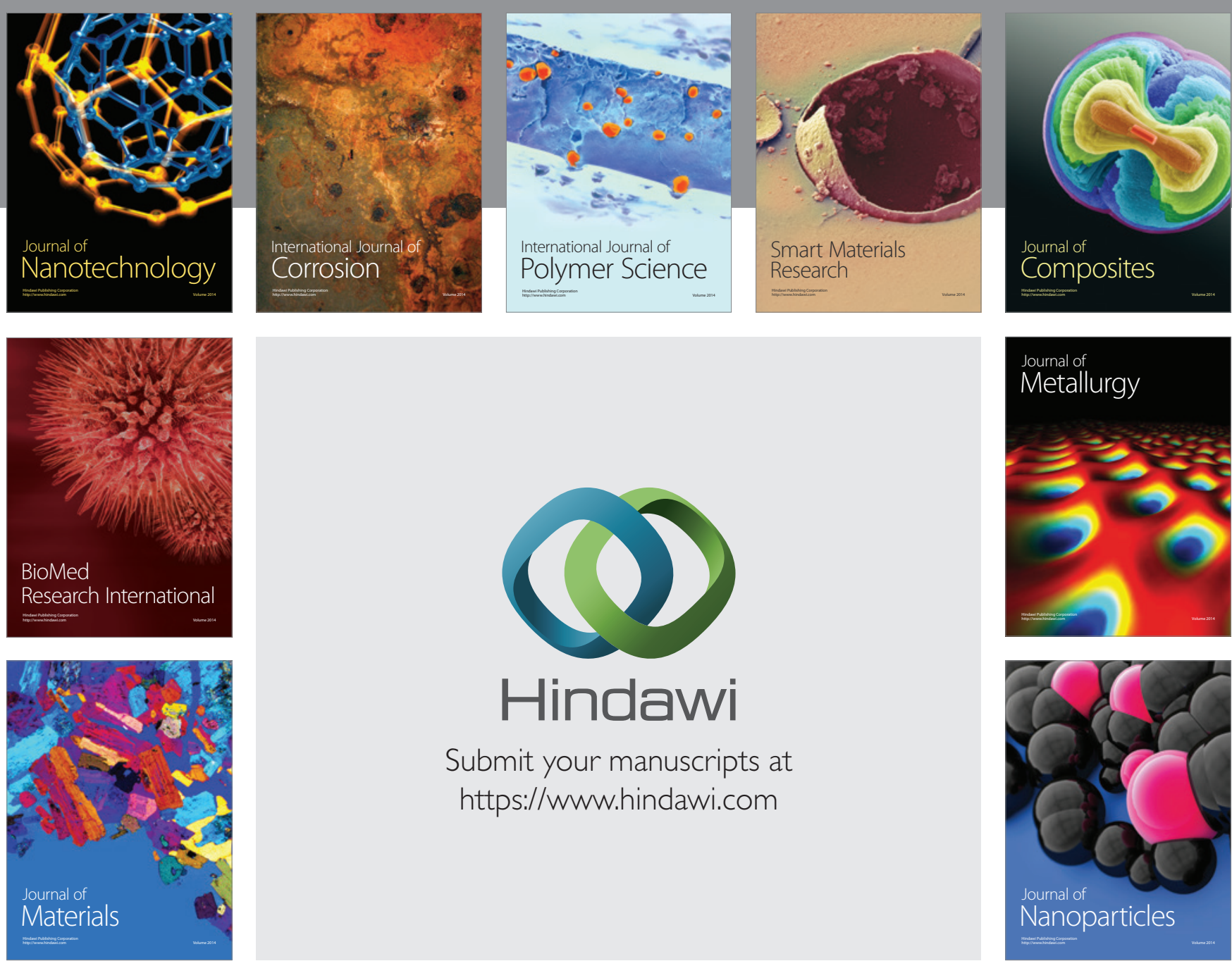

\section{Hindawi}

Submit your manuscripts at

https://www.hindawi.com

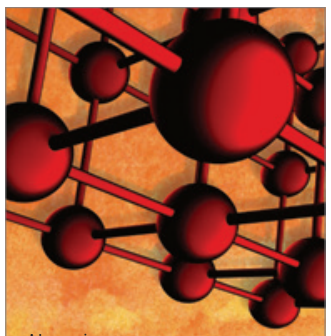

Materials Science and Engineering
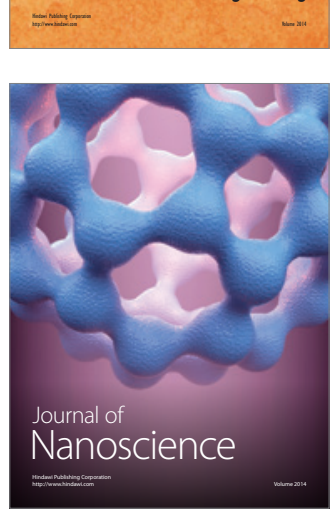
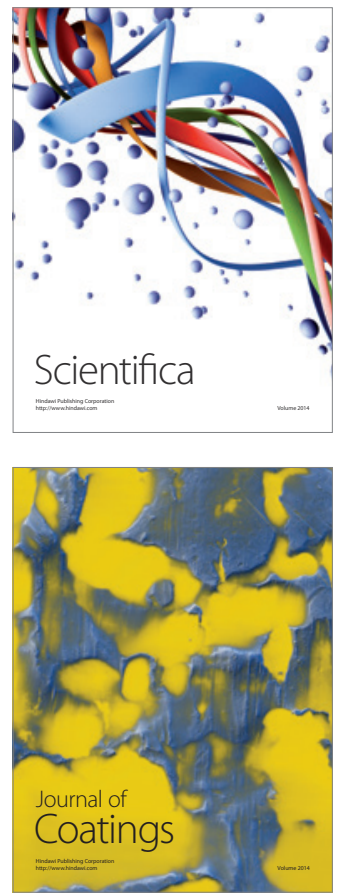
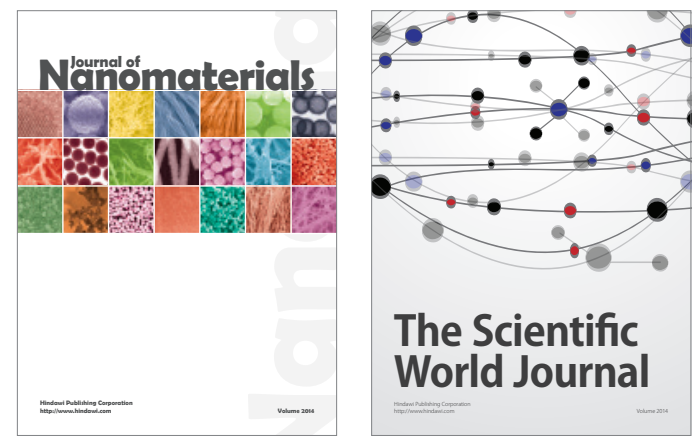

The Scientific World Journal
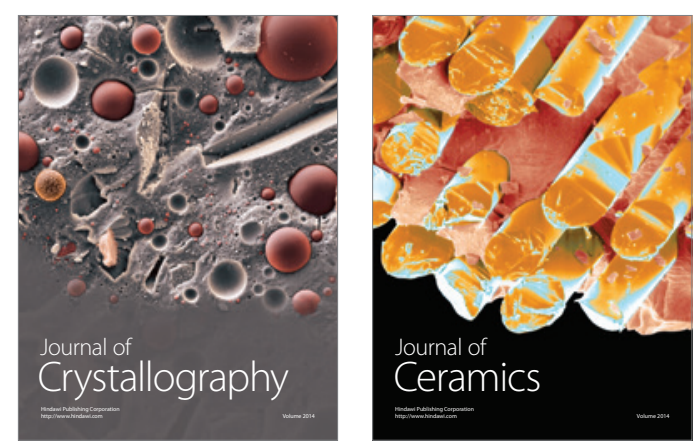
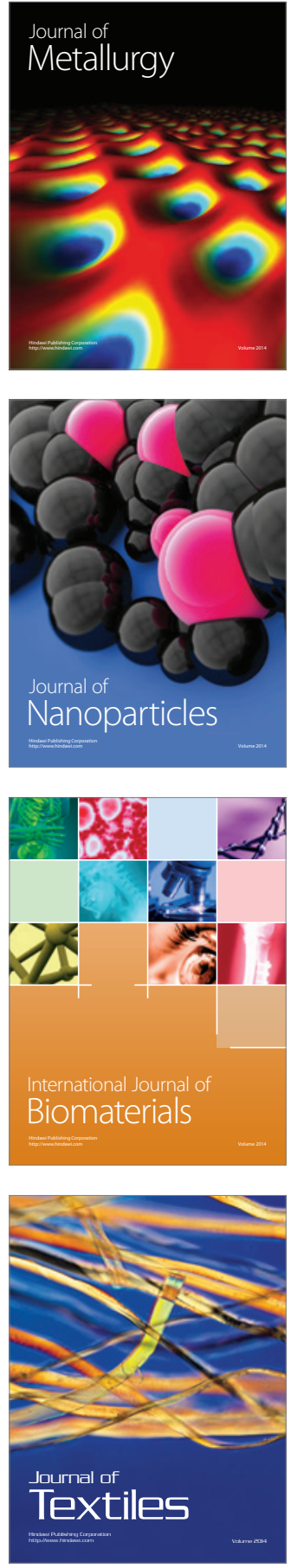